Domestic violence

\section{Unreported cases of domestic violence against women: towards an epidemiology of social silence, tolerance, and inhibition}

\section{Enrique Gracia}

\section{The "iceberg" of domestic violence}

D ata from different surveys indicate a high prevalence of domestic violence against women in all societies. ${ }^{1}$ In western countries it is estimated that about $25 \%$ of women experience intimate partner violence over their lifetimes. ${ }^{2}{ }^{3}$ However, prevalence data show only one side of the problem: the seriousness of the problem in terms of how widespread it is in our societies. Another side of the problem, one that has received less attention, is that most of the cases of domestic violence are unreported. That is, reported cases of domestic violence against women represent only a very small part of the problem when compared with prevalence data. This part of the problem is also known as the "iceberg" of domestic violence. An image where reported cases of domestic violence against women (usually the most severe end of violence) and homicide of women by their intimate partners represents only the tip of the iceberg. According to this metaphor, most of the cases are submerged, allegedly invisible to society.

Domestic violence against women has been considered a very serious public health problem. ${ }^{4}$ But probably few public health problems share this feature of domestic violence against women: a condition affecting about $25 \%$ of the population but only a few of those affected, between $2.5 \%$ and $15 \%,{ }^{5}$ report that they are suffering from that condition. Again, the image of the iceberg tells us that although we can estimate how many women are victims of domestic violence, we are not reaching them because most cases are unreported. This suggests that we are not dealing very well with this problem. Of course, it is important to further understand why female victims of domestic violence don't report or don't seek help. There are still few studies analysing those factors that motivate or inhibit women affected by domestic violence to find a way out. ${ }^{6}$ The reasons so many cases go unreported are both personal (embarrassment, fear of retaliation, economic dependency) and societal (imbalanced power relations for men and women in society, privacy of the family, victim blaming attitudes). But we also need to know whether or not all those unreported cases are really invisible for the social environment surrounding the victims (friends, family, neighbours, social services, public health sector...). And if they are socially visible, but not reported, we need to respond accordingly.

Is the submerged part of the iceberg a matter of ignorance (nobody knows, sees, or hears), or is a matter of social silence and inhibition (people know, but choose not to tell or help)? In an Eurobarometer by the European Commission on "Europeans and their views on domestic violence against women", when people were asked "Do you know a woman who has been a victim of some form of domestic violence?" a substantial percentage knew someone where they work or study, in their neighbourhood, and in their circle of friends and family $(11 \%, 18 \%$, and $19 \%$ respectively). Also the respondents knew someone who had subjected a woman to some form of domestic violence in the same places $(7 \%, 16 \%$, and $17 \%$ respectively). These results suggest that many cases of intimate partner violence, although unreported, are known to the social circle surrounding the victim. While these data support that, especially among friends and family, most cases are known, there is a significant reserve of cases obscured from those close to victims and abusers. The same opinion poll also shows that $46 \%$ of European Union citizens think that the provocative behaviour of women is a cause of domestic violence against women, which indicates a high prevalence of victim blaming attitudes. ${ }^{7}$ And, as social scientists know, being held responsible for their own victimisation reduces significantly the chances of receiving help. ${ }^{8}$ These attitudes also help to maintain a climate of social tolerance for intimate partner violence.

Among the societal factors that influence rates of violence are those that create an acceptable climate for violence. ${ }^{1}$ The silence and inhibition of those who know, and victim blaming attitudes, contribute to create a climate of tolerance that reduces inhibitions against violence, makes it more difficult for women to come forward, and promotes social passivity. ${ }^{6}$ A public education effort is needed to break the silence, to reduce social tolerance, and to increase the level of social responsibility by promoting individual and collective action regarding domestic violence against women. ${ }^{9}$ Zero tolerance campaigns, involving local organisations, community groups, academics, and a highly visible media campaign with the aim of challenging social attitudes towards violence against women by their intimate partners, are a good example of a public education effort to change the social climate of silence, tolerance and inhibition. ${ }^{10}$ Also health professionals can make a big difference in identifying and thus bringing the invisible part of the iceberg into the light. Rates of domestic violence detection in hospitals and emergency rooms are still low despite the fact that a high percentage of female victims of domestic violence visit emergency rooms for treatment. ${ }^{11}$ Health professionals rarely check for signs of violence or ask women about experiences of abuse, ${ }^{1}$ even though most women favour routine questioning by their practitioners about domestic violence. ${ }^{12}$ Although there is still certain controversy about the usefulness of domestic violence screening in general practice and primary care, ${ }^{13}{ }^{14}$ there is a growing recognition of the importance of domestic violence screening as an appropriate and effective means of identifying and responding to domestic violence cases presenting to emergency departments. ${ }^{15}{ }^{16}$ As research has shown, the use of emergency room protocols for identifying and treating victims of domestic violence has been found to increase the identification of victims by medical practitioners from $5.6 \%$ to $30 \% .^{17}$

The line that separates the visible from the invisible part of the iceberg of domestic violence against women is also the line under which starts the silence of the victims as well as the silence, inhibition, and tolerance of the social environment surrounding the victims. By breaking this silence, by reducing the social tolerance and inhibition, and by increasing identification and reporting of domestic violence against women we will also be taking steps to progressively 


\section{Policy implications}

- Public awareness campaigns should also focus on the invisible part of the iceberg of domestic violence against women, pointing out that it is the result not only of the victim's silence but also of the silence, tolerance, and inhibition of the social circles surrounding the victims.

- Public education campaigns need to transmit the idea of social responsibility in issues of domestic violence. Greater social response (in particular of those who know but choose not to tell) would help break the climate of social tolerance, thus increasing the costs for perpetrators, and acting as a deterrent.

- Domestic violence policies should target the reduction of the gap between prevalence estimates and reported cases. These policies would benefit from a greater research focus on societal attitudes towards intimate partner violence issues (reporting, victim blaming, tolerance, inhibition, silence).

- Policies should promote training and education to raise awareness, and to improve identification skills and appropriate responses to the disclosure of intimate partner violence in health settings.

- As policies that are directed to progressively melt the iceberg of domestic violence become more successful, more resources need to be allocated at different levels (health settings, law enforcement, community services, support programmes for the victims).

melt the iceberg of domestic violence. This is an important challenge for western societies (even after more than 25 years of activism in the field of intimate partner violence), but this challenge is even greater in other cultures where violence against women is seen as a natural phenomenon based in deep rooted beliefs and attitudes, and calls for sustained and coordinate actions at community, national, and international levels. ${ }^{1}$ It is clear that better quality prevalence data are needed, because the available statistics do not reflect the pervasiveness of the problem. But prevention policies would also benefit from data monitoring indicators of social silence, inhibition, and tolerance. This could be done, for example, by monitoring changes in the number of cases reported by those who know about the violence (neighbours, relatives, friends, health or law enforcement personnel), as well as changes in social attitudes (such as victim blaming, balance of power between men and women in relationships, or zero tolerance attitudes). When figures converge with the prevalence estimates we would know that something is really changing, that a sizeable proportion of the population no longer tolerates domestic violence against women.

\section{$J$ Epidemiol Community Health} 2004;58:536-537.

doi: 10.1136/jech.2003.019604

Correspondence to: Professor E Gracia, Departamento de Psicología Social, Facultad de Psicología, Universidad de Valencia, Avda Blasco lbañez, 21, 46010 Valencia, Spain; enrique.gracia@uv.es

\section{REFERENCES}

1 World Health Organisation. World report on violence and health. Geneva: World Health Organisation, 2002.

2 Council of Europe. Recommendation $\operatorname{Rec}(2002) 5$ of the Committee of Ministers to member States on the protection of women against violence adopted on 30 April 2002 and explanatory memorandum. Strasbourg, France: Council of Europe, 2002

3 American Medical Association. Diagnostic and treatment guidelines on domestic violence. Chicago, IL: American Medical Association, 1994.

4 Krantz G. Violence against women: a global public health issue. J Epidemiol Community Health 2002;56:242-3.

5 Bachman R, Saltzman L. Bureau of Justice Statistics Special Report: violence against women: Estimates from the redesigned survey (NCJ154348). Washington, DC: US Department of Justice, Bureau of Justice Statistics, 1995.

6 Shrader E, Sagot M. Domestic violence: women's way out. Washington, DC: Pan American Health Organization, 2000, http://www.paho.org/ english/hdp/hdw/womenswayout.pdf; http:// www.paho.org/spanish/hdp/hdw/ rutacritica.pdf [Spanish version].

7 European Commission. Europeans and their views on domestic violence against women. Eurobarometer 51.0. Brussels: European Commission, Directorate General X, 1999.

8 Weiner B. A cognitive (attribution)-emotion-action model of motivated behavior: an analysis of judgments of help giving. J Pers Soc Psychol 1980;39:186-200.

9 Klein E, Campbell J, Soler E, et al. Ending domestic violence: changing public perceptions/ halting the epidemic. London: Sage, 1997.

10 Kitzinger J, Hunt K. Evaluation of Edinburgh District Council's zero tolerance campaign: the full report. Edinburgh: Edinburgh District Council Women's Committee, 1994

11 Abbott J, Johnson R, Koziol-McLain J, et al. Domestic violence against women: incidence and prevalence in an emergency department population. JAMA 1995;273:1763-7.

12 Bradley F, Smith M, Long J, et al. Reported frequency of domestic violence: cross sectional survey of women attending general practice. BMJ 2002;324:1-6.

13 Cole T. Is domestic violence screening helpful? JAMA 2000;284:551-3.

14 Richarson J, Coid J, Petruckevitch A, et al. Identifying domestic violence: cross sectional study in primary care. BMJ 2002;324:274-7.

15 Lo-Vecchio F, Bhatia A, Sciallo D. Screening for domestic violence in the emergency department Eur J Emerg Med 1998;5:441-4.

16 Morrison L, Allan R, Grunfeld A. Improving the emergency department detection rate of domestic violence using direct questioning. J Emerg Med 2000; 19:1 17-24.

17 McLeer S, Anwar R. A study of battered women presenting in an emergency department. Am J Public Health 1989;79:65-6. 